\title{
Flower-like $\mathrm{ZnO}$ hollow microspheres on ceramic mesh substrate for
}

\section{photocatalytic reduction of $\mathrm{Cr}(\mathrm{VI})$ in tannery wastewater}

Junli Liu ${ }^{\mathrm{a}^{*}}$, Yanru Zhao ${ }^{\mathrm{b}}$, Jianzhong $\mathrm{Ma}^{\mathrm{b}}{ }^{* *}$, Yameng Dai ${ }^{\mathrm{a}}$, Junqi $\mathrm{Li}^{\mathrm{a}}$, Jing Zhang ${ }^{\mathrm{c}}$

${ }^{\text {a }}$ College of Materials Science and Engineering, Shaanxi University of Science \& Technology, Xi'an 710021, PR China

${ }^{\mathrm{b}}$ College of Bioresources Chemistry and Materials Engineering, Shaanxi University of Science \& Technology, Xi'an 710021, PR China

${ }^{c}$ College of Arts and Sciences, Shaanxi University of Science \& Technology, Xi'an 710021, PR China

\begin{abstract}
Flower-like $\mathrm{ZnO}$ hollow microspheres were synthesized on flexible ceramic mesh substrate using a simple and economical hydrothermal technique and characterized by X-ray diffraction (XRD), scanning electron microscopy (SEM) and transmission electron microscopy (TEM). The photocatalytic reduction of $\mathrm{Cr}(\mathrm{VI})$ in leather tannery wastewater by flower-like $\mathrm{ZnO}$ hollow microspheres was evaluated under ultraviolet light irradiation for the first time. The addition of different organics and $\mathrm{pH}$ value of the reaction solution played important roles in the photocatalytic reduction of $\mathrm{Cr}(\mathrm{VI})$. In addition, UV radiation intensity and catalyst content were critical parameters in the photocatalytic reduction process and their effects were also investigated. Under the optimal conditions, $\mathrm{ZnO}$ hollow microspheres exhibited excellent removal efficiency of $\mathrm{Cr}(\mathrm{VI})(\sim 86 \%)$ and good photocatalytic stability. Moreover, more than $24 \%$ biochemical oxygen demand $\left(\mathrm{BOD}_{5}\right), 32 \%$ chemical oxygen demand (COD) and 30\% total organic carbon (TOC) of tannery wastewater were reduced significantly after only $180 \mathrm{~min}$ of exposure to the UV lamp. It shows


much promise to be an attractive photocatalyst for photocatalytic application.

Keywords: ZnO, Ceramic mesh substrate, Photocatalytic reduction, $\mathrm{Cr}(\mathrm{VI})$, Tannery wastewater

${ }^{*}$ Corresponding author. Tel.: +86 029 86132559; fax: p86 02986132559.

${ }^{* * *}$ Corresponding author. Tel.: +86 029 86168006; fax: +86 02986168012.

E-mail address: liujunli042@163.com (J. Liu), majz@ sust.edu.cn (J. Ma)

\section{Introduction}

The growth in civilization and industrial activities has caused a great number of environmental problems. For decades, large quantities of pollutants have been discharged into the environment irresponsibly ${ }^{[1-2]}$. Unlike most organic pollutants, metals are particularly problematic because they are not biodegradable and can accumulate in living tissues. Although at low doses some heavy metals are essential micronutrients for plants and animals, in higher doses they can detrimentally affect the health of most living organisms ${ }^{[3-4]}$.

Hexavalent chromium ( $\mathrm{Cr}(\mathrm{VI}))$ is a common heavy metal pollutant in wastewaters, which mainly comes from the irrational release of leather tanning, cooling towers, electroplating wood preservation and steel manufacturing ${ }^{[5-7]}$. The most common chromium oxidation states in nature are $\mathrm{Cr}(\mathrm{III})$ and $\mathrm{Cr}(\mathrm{VI})$. Among them $\mathrm{Cr}(\mathrm{VI})$ is carcinogenic and toxic for the environment and human beings, whereas $\mathrm{Cr}$ (III) is less toxic and can be readily precipitated ${ }^{[8-9]}$. Currently, the methods for the removal of Cr(VI) include adsorption ${ }^{[10-12]}$, biosorption ${ }^{[13]}$, electrocoagulation ${ }^{[14]}$, ion exchange ${ }^{[15-16]}$, membrane filtration ${ }^{[17-18]}$ and photocatalytic reduction ${ }^{[19-21]}$. 
Among those methods, photocatalysis has attracted the attention of the scientific community since it is a an economical, efficient, and clean technology for $\mathrm{Cr}(\mathrm{VI})$ reduction in aqueous media ${ }^{[22-24]}$. Briefly, photocatalytic method is based on the reactive properties of an electron-hole pair generated in the semiconductor when irradiated by UV/vis light having energy greater than the band-gap energy of the semiconductor. If the charge separation is maintained, the electron and hole may migrate to the catalyst surface where they participate in redox reactions with adsorbed species $^{[25-26]}$. It has been shown that the $\mathrm{Cr}(\mathrm{VI})$, highly toxic species, can be reduced to $\mathrm{Cr}$ (III), non-toxic species, with the help of semiconductors and light ${ }^{[27]}$.

Recently, more efforts have been devoted to exploring efficient photocatalyst for $\mathrm{Cr}(\mathrm{VI})$ reduction. Compared to some other semiconductor oxides, Zinc oxide $(\mathrm{ZnO})$ is one of the most popular photocatalysts used in the photodegradation of organic and inorganic compounds, owing to its high activity, low cost and environmental friendliness $^{[28-30]}$. A number of investigations into photo-reduction of $\mathrm{Cr}(\mathrm{VI})$ have been reported ${ }^{[31-33]}$. However, the general effluent in the industry usually consists of wastewater from each batch process and can therefore contain adverse and complex chemical mixture. No doubt that photo-reduction of $\mathrm{Cr}(\mathrm{VI})$ in industrial wastewater will greatly increase the difficulty of photocatalyitc process. To the best of our knowledge, there are few scientific literatures on the treatment of $\mathrm{Cr}(\mathrm{VI})$ photoreduction in leather tannery wastewater. Moreover, most photocatalysts that have been studied previously were mobile-type, and only a few immobilized photocatalysts have been reported although they have clear advantages over 
mobile-type catalysts from a practical perspective. For example, immobilized photocatalysts minimize the power required for mixing and can be recycled without an additional process and operated at flow-type reactors ${ }^{[34]}$.

In this work, flower-like $\mathrm{ZnO}$ hollow microspheres photocatalysts were synthesized on flexible ceramic fibers substrate through a facile hydrothermal method. The photocatalytic performances of the as-synthesized photocatalysts on the photocatalytic reduction of $\mathrm{Cr}(\mathrm{VI})-\mathrm{Cr}(\mathrm{III})$ were investigated in detail and the optimal react conditions were obtained. In addition, $\mathrm{ZnO}$ photocatalysts were used to treat the leather tanning wastewater collected from plant under the optimal conditions and the results were also discussed in this work.

\section{Experimental}

\subsection{Chemicals}

Ceramic fibers, zinc acetate $\left[\mathrm{Zn}(\mathrm{Ac})_{2} \cdot 2 \mathrm{H}_{2} \mathrm{O}\right), 99 \%$, zinc nitrate $\left[\mathrm{Zn}\left(\mathrm{NO}_{3}\right)_{2} \cdot 6 \mathrm{H}_{2} \mathrm{O}\right.$, 99\%], hexamethylenetetramine (HMTA, $\mathrm{C}_{6} \mathrm{H}_{12} \mathrm{~N}_{4}, 99 \%$ ), trisodium citrate $\left(\mathrm{C}_{6} \mathrm{H}_{5} \mathrm{Na}_{3} \mathrm{O}_{7} \cdot 2 \mathrm{H}_{2} \mathrm{O}, 99 \%\right)$, ammonia $\left(\mathrm{NH}_{3} \cdot \mathrm{H}_{2} \mathrm{O}\right)$ of analytical grade were purchased from Tianjin Fuchen Chemical Reagent Co., Ltd. The other chemicals including sodium hydroxide $(\mathrm{NaOH}, 99 \%)$, potassium dichromate $\left(\mathrm{K}_{2} \mathrm{Cr}_{2} \mathrm{O}_{7}, 99.8 \%\right)$, ethanol $\left(\mathrm{CH}_{3} \mathrm{CH}_{2} \mathrm{OH}, 99 \%\right)$, methanol, hydrochloric acid $(\mathrm{HCl}, 36.0-38.0 \%)$, and formic acid were obtained from Tianjin Hongyan Chemical Reagent Co., Ltd.

\subsection{Sample synthesis}

$\mathrm{ZnO}$ hollow microspheres were synthesized on ceramic fibers (CFs) by a simple seed-assisted hydrothermal method. CFs with the area of $2 \mathrm{~cm} \times 3 \mathrm{~cm}$ were washed 
with ethanol and deionized water several times to remove surface impurities. Zero-dimensional $\mathrm{ZnO}$ nanoparticles were first deposited as a seeding layer. Synthesis of $\mathrm{ZnO}$ nanoparticles was carried out by dipping $4 \mathrm{mM}$ concentrations of zinc acetate dehydrate in ethanol for $10 \mathrm{~min}$ and drying in oven at $60{ }^{\circ} \mathrm{C}$ for $10 \mathrm{~min}$ (this process was repeated three times). Then the seed modified CFs were immersed into $200 \mathrm{~mL}$ deionized water in a $250 \mathrm{~mL}$ round flask containing $0.596 \mathrm{~g}$ of $\mathrm{Zn}\left(\mathrm{NO}_{3}\right)_{2} 6 \mathrm{H}_{2} \mathrm{O}, 0.285$ $\mathrm{g}$ of HMTA and $0.107 \mathrm{~g}$ of $\mathrm{C}_{6} \mathrm{H}_{5} \mathrm{Na}_{3} \mathrm{O}_{7} \cdot 2 \mathrm{H}_{2} \mathrm{O}$. After the solution was kept at $80{ }^{\circ} \mathrm{C}$ for 1h, the CFs coated with flowerlike $\mathrm{ZnO}$ hollow microspheres were taken out of the solution and dried in oven at $70{ }^{\circ} \mathrm{C}$, as shown in Fig. S1. (The whole seeding and growth processes were repeated two times. However, the $\mathrm{pH}$ of the mixing solution was adjusted to 10 with $0.2 \mathrm{M} \mathrm{NaOH}$ and kept at $80{ }^{\circ} \mathrm{C}$ for $4 \mathrm{~h}$ in the second growth progress).

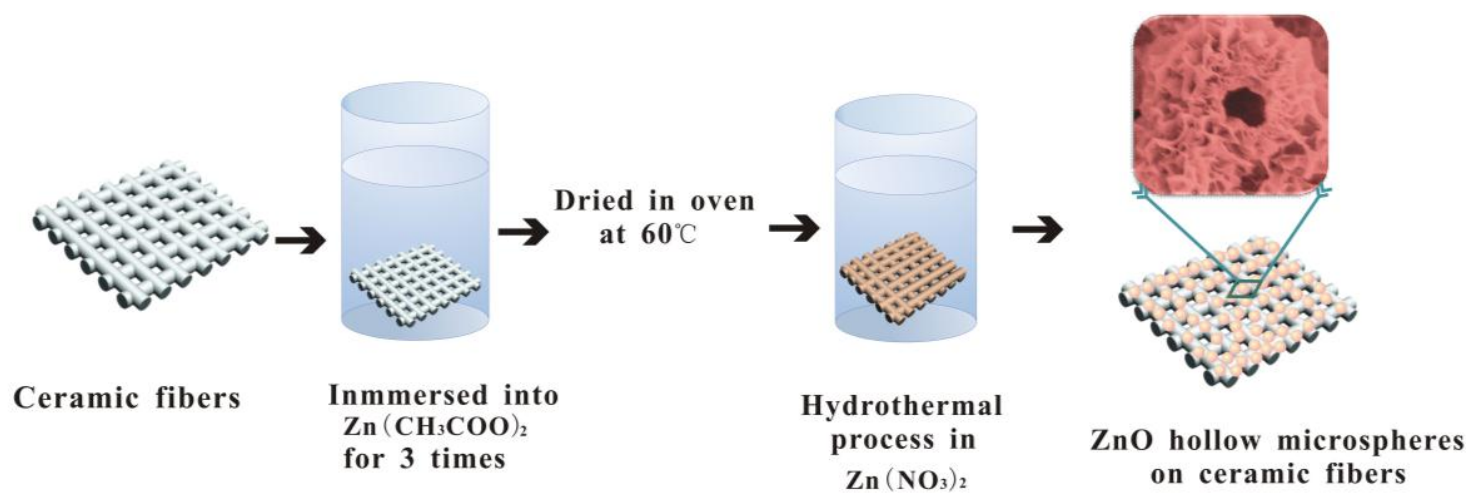

Fig. 1. Scheme illustration for synthesis route of flower-like $\mathrm{ZnO}$ hollow microspheres.

\subsection{Sample characterization}

The morphology and composition of the samples were characterized by scanning electron emission (SEM, S4800, operated at $5.0 \mathrm{kV}$ ) and transmission electron microscope (TEM, JEM-3010, operated at $50 \mathrm{kV}$ ). The crystal structure of the samples was determined by X-ray diffraction (XRD, Rigaku, D/max-2200, Japan) 
with $\mathrm{Cu}$ Ka irradiation at $30 \mathrm{kV}$ and $30 \mathrm{mV}$.

\subsection{Photocatalysis tests}

\subsubsection{Treatment of artificial wastewater}

Photocatalytic activity was first evaluated with a $250 \mathrm{mg} \mathrm{L}^{-1}$ solution of $\mathrm{K}_{2} \mathrm{Cr}_{2} \mathrm{O}_{7}$ prepared in deionized water. The experiment was carried out in a $70 \mathrm{~mL}$ quartz cuvette containing photocatalyst sample $(\mathrm{n} \times 2.0 \mathrm{~cm} \times 3.0 \mathrm{~cm})$ and $50 \mathrm{~mL} \mathrm{Cr}(\mathrm{VI})$ aqueous solution. The solution $\mathrm{pH}$ was adjusted by $0.1 \mathrm{M} \mathrm{HCl}$ and $0.1 \mathrm{M} \mathrm{NaOH}$ solutions. The mixture was stirred and the organic compound (methanol and formic acid) was introduced into the suspension. Prior to irradiation, the suspension was ultrasonicated for $30 \mathrm{~min}$ and magnetically stirred for $1 \mathrm{~h}$ in the dark to ensure adsorption-desorption equilibration. Then the suspensions were irradiated by a $500 \mathrm{~W}$ UV lamp. During illumination, $2 \mathrm{~mL}$ of suspension was taken out from the reactor for test at a scheduled interval.

\subsubsection{Treatment of tannery wastewater}

Reaction conditions were first optimized by artificial wastewater, and under these conditions, tannery wastewater was collected at the outlet of tanning system and taken to the laboratory within $2 \mathrm{~h}$ for same-day processing. The procedure for photocatalytic measurement of wastewater was similar to the degradation of $\mathrm{K}_{2} \mathrm{Cr}_{2} \mathrm{O}_{7}$ as described in artificial wastewater.

\subsection{Analytical procedures}

The concentration of $\mathrm{Cr}(\mathrm{VI})$ was analyzed by the standard diphenylcarbazide colorimetric method at a wavelength of $540 \mathrm{~nm}$ using a TU-1900 Double Beam 
UV-vis Spectrophotometer. The removal of the metal was estimated as a function of irradiation time.

Total organic carbon (TOC) was measured using a Liqui TOC II instrument. Colorimetric method 5220D ${ }^{[35]}$ of Standard Methods procedures was followed by use of a spectrophotomer (Hach Lange DR 1010), employing Pyrex-glass vials, after $2 \mathrm{~h}$ of extreme catalytic oxidation conditions at $150{ }^{\circ} \mathrm{C}$ to analyze the chemical oxygen demand (COD).

Biochemical oxygen demand $\left(\mathrm{BOD}_{5}\right)$ determinations were carried out according to the Standard Methods (HJ 505-2009) ${ }^{[36]}$ by using a BOD Trak II Apparatus (HACH, America). The value reported here is the average of three experiments.

\section{Results and discussion}

\subsection{Morphology and crystal structure}

Figure 1(a) presents a typical low-magnification image of flower-like $\mathrm{ZnO}$ hollow microspheres on ceramic fibers. Because solution-based methods were employed for both $\mathrm{ZnO}$ seed deposition and $\mathrm{ZnO}$ hollow microspheres growth, $\mathrm{ZnO}$ hollow microspheres were uniformly fabricated on the ceramic fibers substrate, which was webbed with round-shaped wires. The enlarged SEM images shown in Fig. 1(b) and (c) suggested that the spheres were actually hollow spheres consisting of numerous nanosheets, which exhibited rather uniform spheres ranging from $1 \mu \mathrm{m}$ to $2 \mu \mathrm{m} \mathrm{nm}$ in diameter. Figure 1(d) shows the TEM image of a typical microsphere, confirming that it is a hollow sphere and the related electron diffraction (ED) pattern shows clear rings characteristic of wurtzite ZnO. The HRTEM image shown in Fig. 1(e) exhibited clear 
lattice fringes with a $d$ spacing of $0.26 \mathrm{~nm}$, which can be indexed to the (002) plane of the wurtzite $\mathrm{ZnO}$ crystal. The XRD pattern of the obtained hollow spheres was shown in Fig. 1(f), which revealed that all the diffraction peaks could be ascribed to $\mathrm{ZnO}$ in the hexagonal wurtzite phase, indicating a pure crystal phase of wurtzite $\mathrm{ZnO}$.
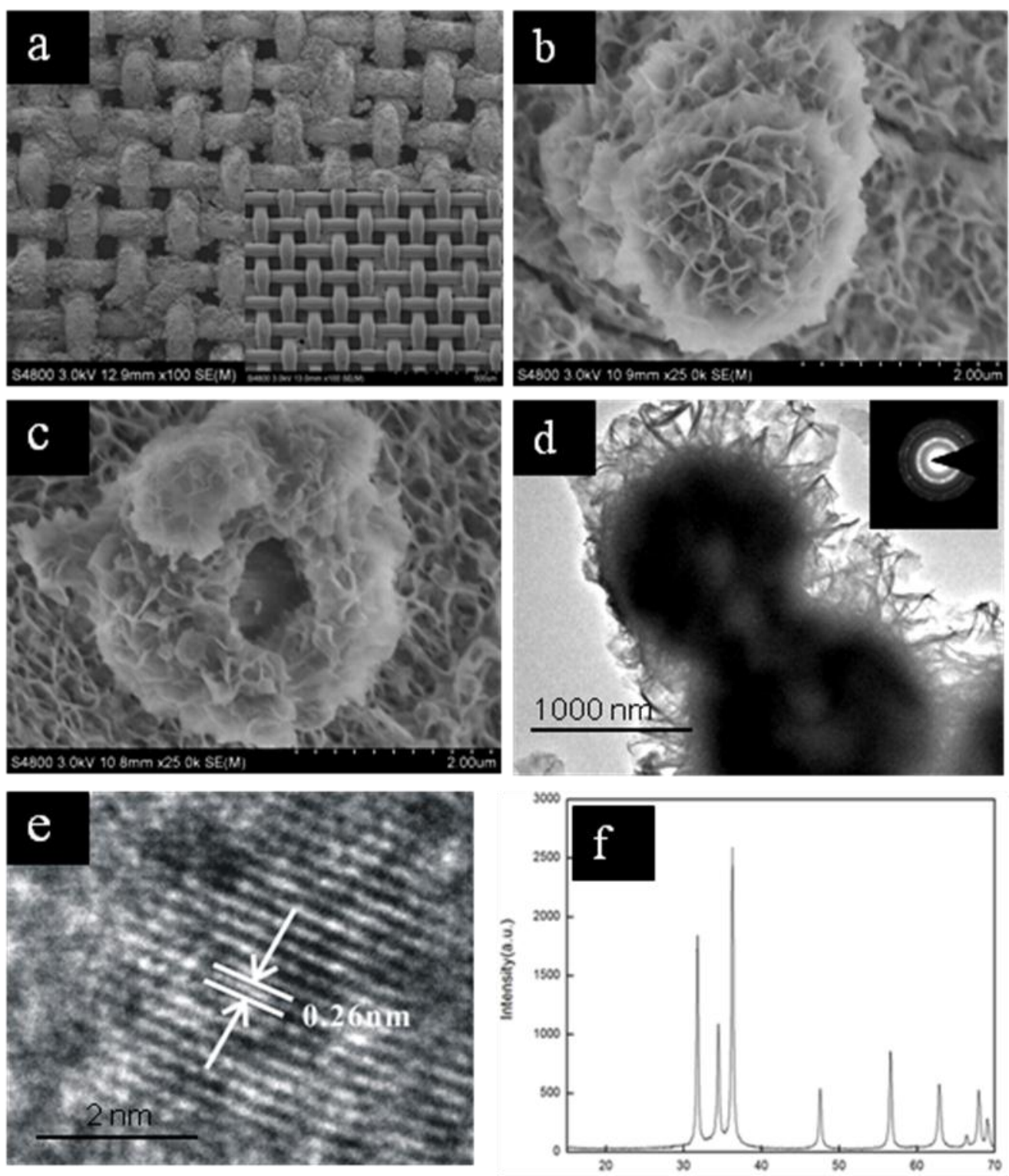

Fig. 2. SEM (a)-(c), TEM (d) and HRTEM (e) images and XRD pattern (f) of ZnO hollow microspheres. Inset shows the related ED pattern.

\subsection{Effects of process parameters on the photocatalytic reduction of $\mathrm{Cr}(\mathrm{VI})$}

Control experiments were carried out to obtain the optimum photocatalytic 
reaction condition. The photocatalytic activity of flower-like $\mathrm{ZnO}$ hollow microspheres was evaluated based on the reduction of $\mathrm{Cr}(\mathrm{VI})$ in the aqueous solution. The major parameters that influence the rate and conversion of $\mathrm{Cr}(\mathrm{VI})$ to $\mathrm{Cr}$ (III) are species of organics, $\mathrm{UV}$ radiation intensity, $\mathrm{pH}$ and number of $\mathrm{ZnO}$ samples. The effects of the parameters were studied over reasonable ranges of their values.

\subsubsection{Effect of the different organics on the photocatalytic reduction process}

The presence of organic matters is inevitable in wastewater containing $\mathrm{Cr}(\mathrm{VI})$. Therefore, it is necessary to investigate how the organic pollutants influence the photocatalytic reduction of $\mathrm{Cr}(\mathrm{VI})^{[37]}$.

As shown in Fig. 3a, the addition of the organics (formic acid and methanol) increased the photocatalytic activity of flower-like $\mathrm{ZnO}$ hollow microspheres for the reduction of $\mathrm{Cr}(\mathrm{VI})$. Compared to formic acid, methanol was found as the more efficient organics for the reduction of $\mathrm{Cr}(\mathrm{VI})$ over flower-like $\mathrm{ZnO}$ hollow microspheres. It was observed that the flower-like $\mathrm{ZnO}$ hollow microspheres and methanol system exhibited the highest reduction ratio (82\%), which was about 1.35 and 1.30 times higher than that of no hole scavenger (63\%) and formic acid (66\%), respectively. The result was also in agreement with the gradual color change of the solution from yellow to laurel-green with irradiation time (inset in Fig. 3a).

This phenomenon was ascribed to holes $\left(\mathrm{h}^{+}\right)$captured at the photocatalyst surface, and holes were able to react with the organic pollutants. This way would suppress electron-hole recombination. Thus, more electrons would escape from the pair recombination and were available to reduce $\mathrm{Cr}(\mathrm{VI})$. These results implied that the 
efficiency of photocatalytic reduction of $\mathrm{Cr}(\mathrm{VI})$ was promoted when the organics such as formic acid and methanol were present in the reaction system. The existence of some organics was beneficial for practical application. As shown in Eq. (1), (2), (3), the facilitated redox process could be outlined. From Fig. 3b, the reduction ratio of $\mathrm{Cr}(\mathrm{VI})$ increased with increasing methanol concentration up to $0.2 \mathrm{~mol} / \mathrm{L}$ while beyond it the value decreased. This was possibly due to an increase intermediates adsorbed onto $\mathrm{ZnO}$ microspheres with the increase of methanol concentration. The active sites would be occupied and the reduction rate was decreased.
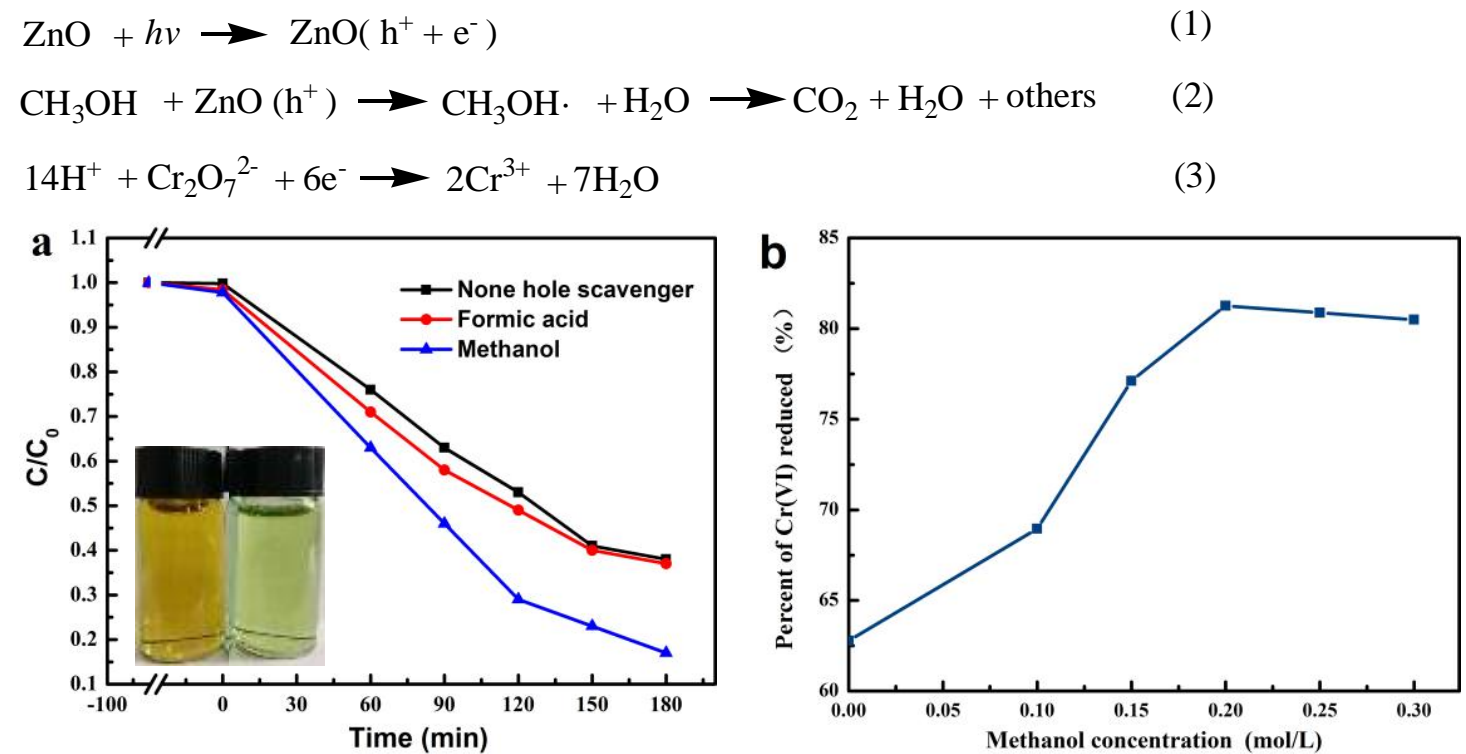

Fig. 3. Photocatalytic reduction of aqueous $\mathrm{Cr}(\mathrm{VI})$ in presence of (a)various organic species and (b)methanol at different concentrations.

\subsubsection{Effect of UV radiation intensity on the photocatalytic reduction process}

The photocatalytic activity of $\mathrm{ZnO}$ hollow microspheres is greatly influenced by the different UV lights and UV radiation intensity. $\mathrm{ZnO}$ is a semiconductor with a band-gap energy $(\approx 3.37 \mathrm{eV}, 370 \mathrm{~nm})$. The high spectral selectivity of the light wavelength less than $370 \mathrm{~nm}$ suggests that it is indeed 'visible-blind' and highly 
UV-sensitive ${ }^{[38]}$. The higher photocatalytic activity was claimed by $\mathrm{Wu}$ et al. with $\mathrm{ZnO}$ under illumination of $350 \mathrm{~nm}$ UV light ${ }^{[39]}$. Also high pressure $\mathrm{Hg}$ lamp as UV light source has been used in most of the previous work. Therefore, the present investigation deals with the $\mathrm{Cr}(\mathrm{VI})$ removal from water system using a $365 \mathrm{~nm}$ high pressure $\mathrm{Hg}$ lamp. However, few researches reported the effect of UV radiation intensity on the photocatalytic activities.

The effect of UV radiation intensity on photocatalytic reduction of $\mathrm{Cr}(\mathrm{VI})$ was mainly investigated in this work and the obtained results were presented in Fig. 4. The power of the UV lamp could be varied from 200 to $500 \mathrm{~W}$. As shown in the curves, the reduction efficiency of $\mathrm{Cr}(\mathrm{VI})$ were $80 \%, 82 \%$ and $86 \%$ at $200 \mathrm{~W}, 300 \mathrm{~W}$, and 400 $\mathrm{W}$, respectively. These observations indicated that the UV radiation intensity has no significant influence on the photocatalytic reduction of $\mathrm{Cr}(\mathrm{VI})$. It appeared that the conversion reached a maximum of about $86 \%$ at $400 \mathrm{~W}$ but decreased with increasing radiation intensity. The slight decrease of the conversion might be attributed to the photo-corrosion due to higher UV radiation intensity on the photocatalysts.

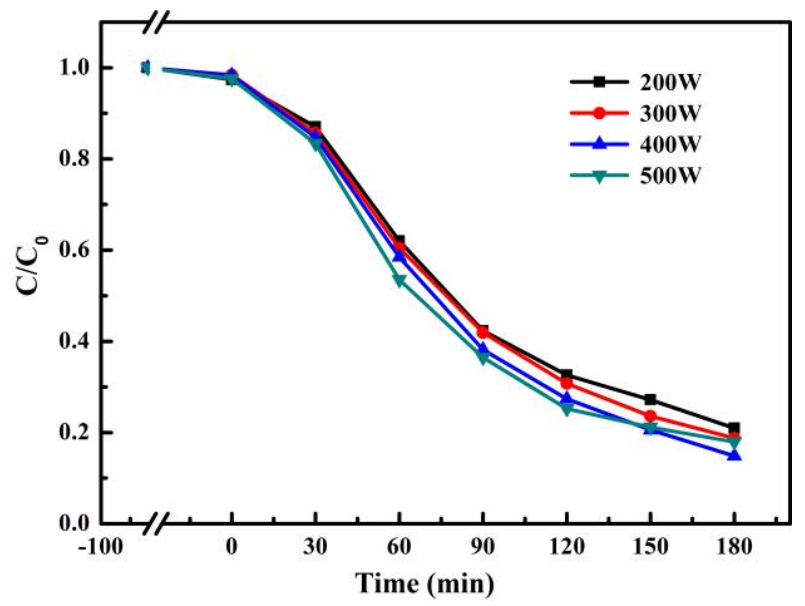

Fig. 4. Effect of UV radiation intensity on photocatalytic reduction of aqueous $\mathrm{Cr}(\mathrm{VI})$.

3.2.3 Effect of $\mathrm{pH}$ value on the photocatalytic reduction process 
The $\mathrm{pH}$ of the solution is an important parameter in photocatalytic processes. A few experiments for $180 \mathrm{~min}$ at different $\mathrm{pH}$ values were conducted. The corresponding fractional reduction of $\mathrm{Cr}(\mathrm{VI})$ was presented in Fig. 5. It appears that the conversion reaches a maximum of about $90 \%$ at a $\mathrm{pH} 5$ but decreases rapidly with increasing $\mathrm{pH}$. The range of $\mathrm{pH}$ for the photocatalytic reduction of $\mathrm{Cr}(\mathrm{VI})$ using $\mathrm{ZnO}$ is rather limited. The catalyst dissolves at a low $\mathrm{pH}$; a high $\mathrm{pH}$ is detrimental to both the catalyst and the oxidizing species. The Nernst equation of the over reaction in this system can be expressed as the following ${ }^{[40-41]}$ :

$\varphi=\varphi^{\theta}+\frac{0.059}{24} \lg \frac{\left[\mathrm{Cr}_{2} \mathrm{O}_{7}^{2+}\right]_{4} \cdot\left[\mathrm{C}_{6} \mathrm{H}_{5} \mathrm{O}_{7}^{3-}\right] \cdot\left[\mathrm{H}^{+}\right]^{41}}{\left[\mathrm{Cr}^{3+}\right]^{8} \cdot\left[\mathrm{CO}_{2}\right]^{6} \cdot\left[\mathrm{H}_{2} \mathrm{O}\right]^{23}}$

The $\varphi$ value increases with the increasing concentration of $\mathrm{H}^{+}$according to Eq. (4). The equilibrium-reaction would move toward right at increased $\varphi$ value, meaning that the reduction rate of $\mathrm{Cr}(\mathrm{VI})$ would be improved in solution with higher acidity. It is apparent that the acid medium facilitates the photocatalytic reduction of $\mathrm{Cr}(\mathrm{VI})$ because of the existence of abundant $\mathrm{H}^{+}$.

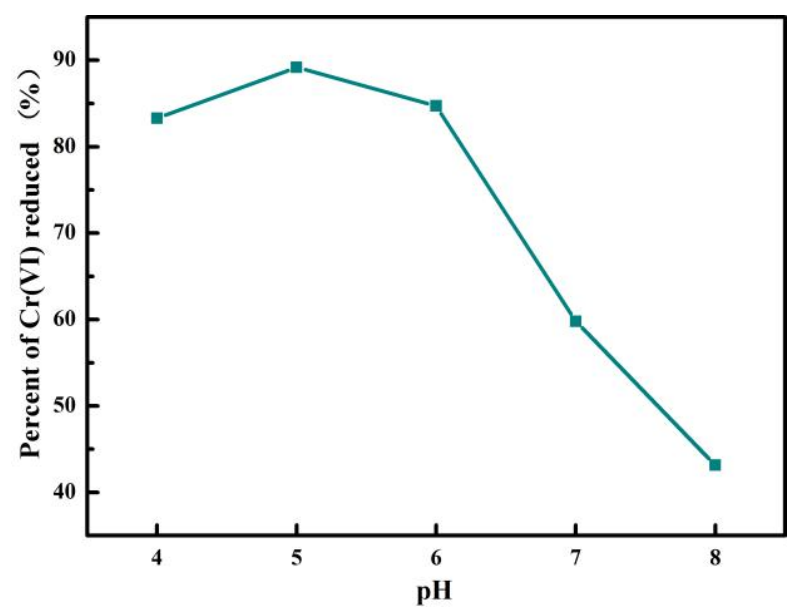

Fig. 5. Photocatalytic reduction efficiencies of aqueous $\mathrm{Cr}(\mathrm{VI})$ under different $\mathrm{pH}$ values.

3.2.4 Effect of number of samples on the photocatalytic reduction process 
$\mathrm{ZnO}$ sample was varied ranging from monolayer $(1 \times 2 \mathrm{~cm} \times 3 \mathrm{~cm})$ to penta-layer $(5 \times 2 \mathrm{~cm} \times 3 \mathrm{~cm})$ while other parameters kept constant in the experiment to investigate the effect of photocatalyst dosage on the photocatalytic reduction of Cr(VI). As can be seen from Fig. 6, with the increasing photocatalyst dosage from monolayer to trilayer, the photocatalytic reduction of $\mathrm{Cr}(\mathrm{VI})$ was increased from $89.8 \%$ to $92.6 \%$, respectively, while a further increase in $\mathrm{ZnO}$ samples (from trilayer to tetra-layer) was not found to be much beneficial for the photocatalytic reduction of $\mathrm{Cr}(\mathrm{VI})$. When the $\mathrm{ZnO}$ samples were increased to penta-layer, the reduction rate was decreased. As the other parameters, such as exposure to a constant UV radiation intensity, $\mathrm{Cr}(\mathrm{VI})$ concentration, $\mathrm{pH}$ value, and irradiation time, etc. were kept constant, further increasing the number of samples beyond optimum dosage failed to contribute significantly to the reduction process. When the dosage of the $\mathrm{ZnO}$ samples was very high, after traversing a certain optical path, $\mathrm{ZnO}$ particles impeded further penetration of UV light in the reactor (incidence of the combined phenomena of particle masking and scattering), lowering the efficiency of the catalytic process.

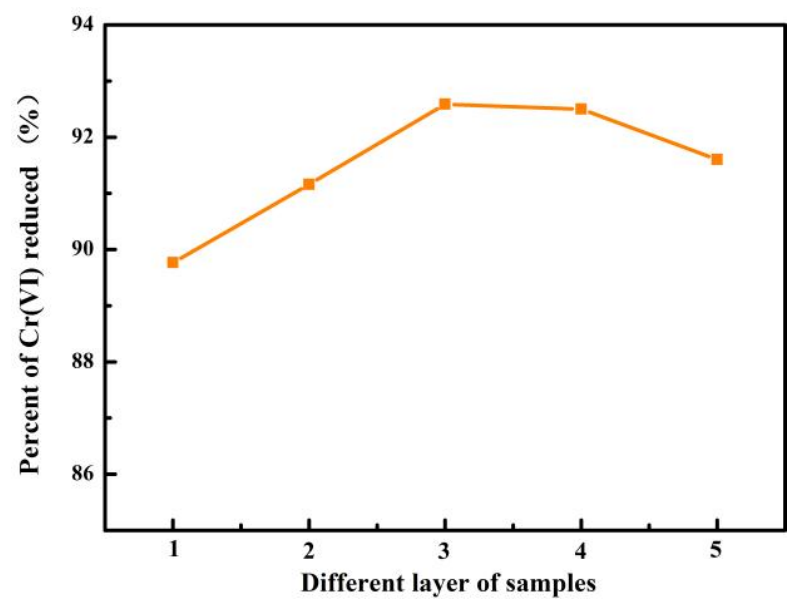

Fig. 6. Effect of different layer of sample on the photocatalytic reduction of $\mathrm{Cr}(\mathrm{VI})$.

3.3 Treatment of real tannery wastewater 
The photocatalyst samples $(3 \times 2 \mathrm{~cm} \times 3 \mathrm{~cm})$ were used to study the reduction of $\mathrm{Cr}(\mathrm{VI})$ of tannery wastewater under $400 \mathrm{~W}$ UV lamp. The procedure for photocatalytic reduction measurement of wastewater was similar to reduction of artificial wastewater as described in section 2.4.1; but the measured $\mathrm{pH}$ was changed to 5 and the amount of added methanol was $2.0 \mathrm{~mol} / \mathrm{L}$. As displayed in Table 1, about $85 \%$ reduction of $\mathrm{Cr}(\mathrm{VI})$ could be achieved before and after UV photocatalytic treatment using $\mathrm{ZnO}$ catalyst. For practical application, researchers were widely concerned about the durability properties of the photocatalysts. Thus the renewable photocatalytic activity was investigated in this study. The experiments were conducted for $3 \mathrm{~h}$ with the same set of photocatalysts but wastewater was replenished every time. The result was presented in the same manner as shown in Fig. 7, from which we can see that after 4 photocatalytic cycles, more than $79 \%$ of $\mathrm{Cr}(\mathrm{VI})$ was reduced within $180 \mathrm{~min}$, indicating the relative stable photocatalytic activity of the flower-like $\mathrm{ZnO}$ hollow microspheres. The photocorrosion of $\mathrm{ZnO}$ might be one of the factors which led to the degradation of photocatalytic activity. ${ }^{[42-44]}$ Furthermore, the reason leading to the decline of photocatalytic activity also can be attributed to the adsorption of $\mathrm{Cr}(\mathrm{VI})$ onto $\mathrm{ZnO}$ microspheres surface for blocking the adsorption of methanol, since $\mathrm{Cr}(\mathrm{VI})$ showed a stronger affinity to $\mathrm{ZnO}$. 


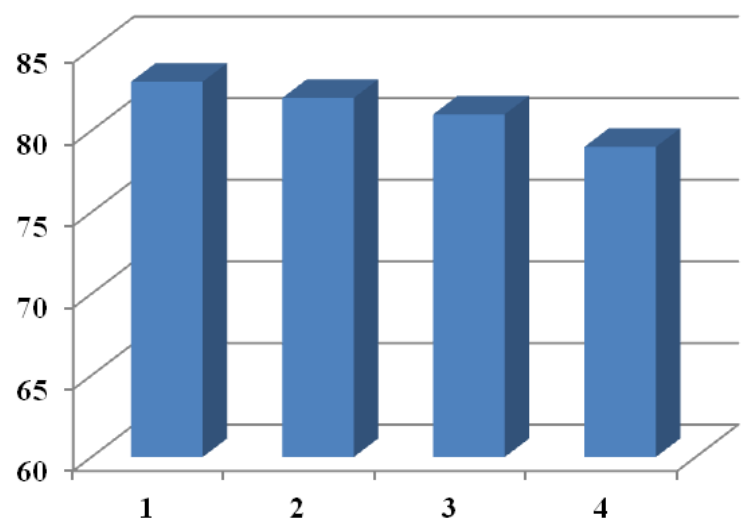

Fig. 7. Cyclic photoreduction rate constants for $\mathrm{Cr}(\mathrm{VI})$ on $\mathrm{ZnO}$ samples

$\mathrm{BOD}_{5}, \mathrm{COD}$ and $\mathrm{TOC}$ are some main parameters in assessing the quality of tannery wastewater. All of these may influence the quality of the wastewater. Table 1 also shows the normalized $\mathrm{BOD}_{5}, \mathrm{COD}$ and $\mathrm{TOC}$ removal during the photocatalytic treatment with the optimal conditions of catalysts. It can be observed that more than $24 \% \mathrm{BOD}_{5}, 32 \% \mathrm{COD}$ and $30 \%$ TOC of wastewater can be reduced significantly after only $180 \mathrm{~min}$ of exposure to the UV lamp. Thus, flower-like $\mathrm{ZnO}$ hollow microspheres can be ideal supported photocatalysts for photocatalytic application.

\section{Table 1}

Related parameters of tannery wastewater before and after treatment

\begin{tabular}{lllll}
\hline Tannery wastewater & $\mathrm{Cr}(\mathrm{VI})$ & BOD $_{5}$ & COD $_{\mathrm{Cr}}$ & TOC \\
\hline Before treatment $\left(\mathrm{mg} \mathrm{L}^{-1}\right)$ & 246 & 290 & 1716 & 1277 \\
\hline After treatment $\left(\mathrm{mg} \mathrm{L}^{-1}\right)$ & 42 & 220 & 1161 & 905 \\
\hline Removal $(\%)$ & 83 & 24 & 32 & 30 \\
\hline
\end{tabular}

Average value of three experiments.

\section{Conclusion}

In summary, the application of flower-like $\mathrm{ZnO}$ hollow microspheres on flexible 
ceramic mesh substrate was considered for the photocatalytic reduction of $\mathrm{Cr}(\mathrm{VI})$ in leather tannery wastewater. The results indicated high efficiency of flower-like $\mathrm{ZnO}$ hollow microspheres for the photocatalytic reduction of $\mathrm{Cr}(\mathrm{VI})(86 \%)$ under UV light irradiation. The addition of methanol facilitated the photocatalytic $\mathrm{Cr}(\mathrm{VI})$ reduction due to its ability to adsorb on the catalyst surface and easy mineralization. Low $\mathrm{pH}$ value of the aqueous solution was also crucial to the reduction of $\operatorname{Cr}(\mathrm{VI})$ due to the $\mathrm{Cr}(\mathrm{VI})$ species and the protonated degree of the photocatalyst surface. Moreover, the rather higher dosage of photocatalysts was detrimental improving the efficiency of photocatalytic because it impeded the further penetration of UV light. Furthermore, the samples possess good photocatalytic stability, which is advantageous to practical applications. This work demonstrates that the flower-like $\mathrm{ZnO}$ hollow microspheres on flexible ceramic mesh substrate are effective materials for photocatalytic reduction of $\mathrm{Cr}(\mathrm{VI})$, which may also have potential applications in photocatalytic removal of other pollutants.

\section{Acknowledgments}

This investigation was supported by Natural Science Basic Research Plan in Shaanxi Province of China (2014JQ6209), Science and Technology Project of Xi'an City(CXY1430), National Science Foundation of Shaanxi University of Science \& Technology(BJ13-23).

\section{References}

[1] H. Lahmar, M. Kebir, N. Nasrallah, M. Trari, Photocatalytic reduction of Cr(VI) on the new hetero-system $\mathrm{CuCr}_{2} \mathrm{O}_{4} / \mathrm{ZnO}$, Journal of Molecular Catalysis A: 
Chemical, 353 (2012) 74-79.

[2] R.P. Cavalcante, R.F. Dantas, H Wender, B. Bayarri, O. González, J Giménez, S Esplugasd, M.J. Amilcar, Photocatalytic treatment of metoprolol with B-doped $\mathrm{TiO}_{2}$ : Effect of water matrix, toxicological evaluation and identification of intermediates, Applied Catalysis B: Environmental, 176 (2015) 173-182.

[3] C.E Barrera-Díaz, V Lugo-Lugo, B Bilyeu, A review of chemical, electrochemical and biological methods for aqueous $\mathrm{Cr}$ (VI) reduction, Journal of hazardous materials, 223 (2012) 1-12.

[4] R Qiu, D Zhang, Z Diao, Z Diao, X Huang, C He, J.L Morel, Y Xiong, Visible light induced photocatalytic reduction of $\mathrm{Cr}(\mathrm{VI})$ over polymer-sensitized $\mathrm{TiO}_{2}$ and its synergism with phenol oxidation, water research, 46 (7) (2012) 2299-2306.

[5] G Dong, L Zhang, Synthesis and enhanced Cr(VI) photoreduction property of formate anion containing graphitic carbon nitride, Journal of Physical Chemistry C, 117 (8) (2013) 4062-4068.

[6] L Wang, X Li, W Teng, Q Zhao, Y Shi, R Yue, Y Chen, Efficient photocatalytic reduction of aqueous $\mathrm{Cr}(\mathrm{VI})$ over flower-like $\mathrm{SnIn}_{4} \mathrm{~S}_{8}$ microspheres under visible light illumination, Journal of hazardous materials, 244 (2013) 681-688.

[7] L Yang, Y Xiao, S Liu, Y Li, Q Cai, S Luo, G Zeng, Photocatalytic reduction of $\mathrm{Cr}(\mathrm{VI})$ on $\mathrm{WO}_{3}$ doped long $\mathrm{TiO}_{2}$ nanotube arrays in the presence of citric acid, Applied Catalysis B: Environmental, 94 (1) (2010) 142-149.

[8] H Wang, X Yuan, Y Wu, G Zeng, X Chen, L Leng, Z Wu, L Jiang, H Li, Facile 
synthesis of amino-functionalized titanium metal-organic frameworks and their superior visible-light photocatalytic activity for $\mathrm{Cr}(\mathrm{VI})$ reduction, Journal of hazardous materials, 286 (2015) 187-194.

[9] C Mondal, M Ganguly, J Pal, A Roy, J Jana, T Pal, Morphology Controlled Synthesis of $\mathrm{SnS}_{2}$ Nanomaterial for Promoting Photocatalytic Reduction of Aqueous Cr(VI) under Visible Light, Langmuir, 30 (14) (2014) 4157-4164.

[10]C.P Huang, A.R Bowers, Activated carbon processes for the treatment of Chromium (VI)-containing industrial wastewaters, Water science and technology, 13 (1) (1980) 629-49.

[11]V.K Gupta, S Agarwal, T.A Saleh, Chromium removal by combining the magnetic properties of iron oxide with adsorption properties of carbon nanotubes, Water research, 45 (6) (2011) 2207-2212.

[12]T Chen, T Wang, D Wang, H Xue, J Zhao, X Ding, S Wu, J He, Synthesis of ordered large-pore mesoporous carbon for $\mathrm{Cr}(\mathrm{VI})$ adsorption, Materials Research Bulletin, 46 (9) (2011) 1424-1430.

[13]G.Q Chen, W.J Zhang, G.M Zeng, J.H Huang, L Wang, G.L Shen, Surface-modified Phanerochaete chrysosporium as a biosorbent for $\mathrm{Cr}$ (VI)-contaminated wastewater, Journal of hazardous materials, 186 (2) (2011) $2138-2143$.

[14]M.S Bhatti, A.S Reddy, R.K Kalia, A.K Thukral, Modeling and optimization of voltage and treatment time for electrocoagulation removal of hexavalent chromium, Desalination, 269 (1) (2011) 157-162. 
[15]S Edebali, E Pehlivan, Evaluation of Amberlite IRA96 and Dowex $1 \times 8$ ion-exchange resins for the removal of $\mathrm{Cr}$ (VI) from aqueous solution, Chemical Engineering Journal, 161 (1) (2010) 161-166.

[16]Y Deng, $\mathrm{T}$ Long, $\mathrm{H}$ Zhao, $\mathrm{L}$ Zhu, J Chen, Application of porous $\mathrm{N}$-methylimidazolium strongly basic anion exchange resins on $\mathrm{Cr}$ (VI) adsorption from electroplating wastewater, Separation Science and Technology, 47 (2) (2012) 256-263.

[17]W Zhang, J Liu, Z Ren, S Wang, C Du, J Ma, Kinetic study of chromium (VI) facilitated transport through a bulk liquid membrane using tri-n-butyl phosphate as carrier, Chemical Engineering Journal, 150 (1) (2009) 83-89.

[18]P.S. Kulkarni, V. Kalyani, V.V. Mahajani, Removal of hexavalent chromium by membrane-based hybrid processes, Ind. Eng. Chem. Res. 46 (2007) 8176-8182.

[19]X Zhao, L Qi, Rapid microwave-assisted synthesis of hierarchical ZnO hollow spheres and their application in Cr (VI) removal, Nanotechnology, 23 (23) (2012) 235604.

[20]M Naimi-Joubani, M Shirzad-Siboni, J.K Yang, M Gholami, M Farzadkia, Photocatalytic reduction of hexavalent chromium with illuminated $\mathrm{ZnO} / \mathrm{TiO}_{2}$ composite, Journal of Industrial and Engineering Chemistry, 22 (2015) 317-323.

[21]J Wang, X Li, X Li, J Zhu, H Li, Mesoporous yolk-shell $\mathrm{SnS}_{2}-\mathrm{TiO}_{2}$ visible photocatalysts with enhanced activity and durability in $\mathrm{Cr}$ (vi) reduction, Nanoscale, 5 (5) (2013) 1876-1881.

[22]C Alanis, R Natividad, C Barrera-Diaz, V Martinez-Miranda, J Prince, J Valente, 
Photocatalytically enhanced Cr (VI) removal by mixed oxides derived from MeAl (Me: Mg and/or Zn) layered double hydroxides, Applied Catalysis B: Environmental, 140 (2013) 546-551.

[23]J Yu, S Zhuang, X Xu, W Zhu, B Feng, J Hu, Photogenerated electron reservoir in hetero-p-n $\mathrm{CuO}-\mathrm{ZnO}$ nanocomposite device for visible-light-driven photocatalytic reduction of aqueous Cr (vi), Journal of Materials Chemistry A, 3 (3) (2015) 1199-1207.

[24]S Chakrabarti, B Chaudhuri, S Bhattacharjee, A Ray, B Dutta, Photo-reduction of hexavalent chromium in aqueous solution in the presence of zinc oxide as semiconductor catalyst, Chemical Engineering Journal, 153 (1) (2009) 86-93.

[25]C Alanis, R Natividad, C Barrera-Diaz, V Martinez-Miranda, J Prince, J Valente, Photocatalytically enhanced Cr (VI) removal by mixed oxides derived from MeAl (Me: Mg and/or Zn) layered double hydroxides, Applied Catalysis B: Environmental, 140 (2013) 546-551.

[26]J Zhen, Y Zhang, F Meng, Y Jia, L Tao, X Yu. J Wang, J Liu, X Huang, Facile synthesis of porous single crystalline $\mathrm{ZnO}$ nanoplates and their application in photocatalytic reduction of $\mathrm{Cr}$ (VI) in the presence of phenol, Journal of hazardous materials, 276 (2014) 400-407.

[27]H Wang, X Yuan, Y Wu, G Zeng, X Chen, L Leng, Z Wu, L Jiang, H Li, Facile synthesis of amino-functionalizedtitanium metal-organic frameworks and their superior visible-light photocatalytic activity for $\mathrm{Cr}(\mathrm{VI})$ reduction, Journal of hazardous materials, 286 (2015) 187-194. 
[28]W Liu, M Wang, $\mathrm{C} \mathrm{Xu}$, S Chen, Facile synthesis of $\mathrm{gC}_{3} \mathrm{~N}_{4} / \mathrm{ZnO}$ composite with enhanced visible light photooxidation and photoreduction properties, Chemical Engineering Journal, 209 (2012) 386-393.

[29]J.M Wu, W.T Kao. Heterojunction Nanowires of Ag x Zn1-xO-ZnO Photocatalytic and Antibacterial Activities under Visible-Light and Dark Conditions, Journal of Physical Chemistry C, 119 (3) (2015) 1433-1441.

[30]O.K Ranasingha, C Wang, P.R Ohodnicki, J.W Lewis, C Matranga, Synthesis, characterization, and photocatalytic activity of $\mathrm{Au}-\mathrm{ZnO}$ nanopyramids, Journal of Materials Chemistry A, 3 (29) (2015) 15141-15147.

[31]L.S Zhong, J.S Hu, H.P Liang, A.M Cao, W.G Song, L.J. Wan, Self-Assembled 3D flowerlike iron oxide nanostructures and their application in water treatment,. Advanced Materials, 18 (18) (2006) 2426-2431.

[32]J Wang, X Li, X Li, J Zhu, H Li, Mesoporous yolk-shell $\mathrm{SnS}_{2}-\mathrm{TiO}_{2}$ visible photocatalysts with enhanced activity and durability in $\mathrm{Cr}$ (vi) reduction, Nanoscale, 5 (5) (2013) 1876-1881.

[33]Padhi D K, Parida K, Facile fabrication of $\alpha$-FeOOH nanorod/RGO composite: a robust photocatalyst for reduction of $\mathrm{Cr}$ (VI) under visible light irradiation, Journal of Materials Chemistry A, 2 (26) (2014) 10300-10312.

[34]Jung S, Yong K, Fabrication of $\mathrm{CuO}-\mathrm{ZnO}$ nanowires on a stainless steel mesh for highly efficient photocatalytic applications, Chemical Communications, 47 (9) (2011) 2643-2645.

[35] Standard Methods for the Examination of Water and Wastewater, 21st ed., 
American Public Health Association/American Water Works Association/Water Pollution Control Federation, Washington, DC, USA (2005).

[36]Chinese National Standard Methods, Water quality-Determination of biochemical oxygen demand after 5 days (BOD5) for dilution and seeding method, HJ 505-2009.

[37]Wang L, Li X, Teng W, et al. Efficient photocatalytic reduction of aqueous Cr (VI) over flower-like $\mathrm{SnIn}_{4} \mathrm{~S}_{8}$ microspheres under visible light illumination[J]. Journal of hazardous materials, 2013, 244: 681-688.

[38]L Hu, M Chen, W Shan, $\mathrm{T}$ Zhan, M Liao, X Fang, X Hu, L Wu, Stacking-order-dependent optoelectronic properties of bilayer nanofilm photodetectors made from hollow $\mathrm{ZnS}$ and $\mathrm{ZnO}$ microspheres, Advanced Materials, 24 (43) (2012) 5872-5877.

[39]M Chen, L Hu, J Xu, M Liao, L Wu, ZnO Hollow-Sphere Nanofilm-Based High-Performance and Low-Cost Photodetector, Small, 7 (17) (2011) 2449-2453. [40]L Yang, Y Xiao, S Liu, Y Li, Q Cai, S Luo, G Zeng, Photocatalytic reduction of $\mathrm{Cr}(\mathrm{VI})$ on $\mathrm{WO}_{3}$ doped long $\mathrm{TiO}_{2}$ nanotube arrays in the presence of citric acid, Applied Catalysis B: Environmental, 94 (1) (2010) 142-149.

[41]M Qamar, M.A Gondal, Z.H Yamani, Laser-induced efficient reduction of Cr (VI) catalyzed by $\mathrm{ZnO}$ nanoparticles, Journal of hazardous materials, 187 (1) (2011) 258-263.

[42]Y Li, W Xie, X Hu, G Shen, X Zhou, Y Xiang, X Zhao, P Fang, Comparison of dye photodegradation and its coupling with light-to-electricity conversion over 
$\mathrm{TiO}_{2}$ and $\mathrm{ZnO}$, Langmuir, 26 (1) (2009) 591-597.

[43]W Xie, Y Li, W Sun, J Huang, H Xie, X Zhao, Surface modification of ZnO with Ag improves its photocatalytic efficiency and photostability, Journal of Photochemistry and Photobiology A: chemistry, 216 (2) (2010) 149-155.

[44]Z Jin, Y.X Zhang, F.L Meng, Y Jia, T Luo, X.Y Yu, J Wang, J.H Liu, X.J Huang, Facile synthesis of porous single crystalline $\mathrm{ZnO}$ nanoplates and their application in photocatalytic reduction of $\mathrm{Cr}$ (VI) in the presence of phenol, Journal of hazardous materials, 276 (2014) 400-407. 